\title{
Agua, memoria e identidad en Le voyage des âmes (1997) de Mounsi
}

\section{Cases-Muñoz, David}

Universitat de València, dacamu@alumni.uv.es

\begin{abstract}
Resumen
El escritor francés Mohand Mounsi retoma la escritura autobiográfica en su tercera novela publicada, Le voyage des âmes, para narrarnos el periplo personal de ese niño de siete años desde su Cabila natal a la bidonville de Nanterre. En este viaje al interior de los recuerdos y de la reconstrucción de la memoria y de la identidad intercultural, el agua jugará un papel preponderante, especialmente en los rituales propios de la cultura beréber. Destaca en especial toda la transmisión efectuada por la abuela Zina, esa maga que lo ha iniciado e instruido en el respeto de la naturaleza a través de la narración de cuentos y leyendas autóctonas donde el simbolismo del agua es muy marcado. Se trata de una escritura donde se rememoran rituales en los que el agua es un elemento central, o bien comunitarios, como para proteger a los difuntos en su paso entre la vida y la muerte, o bien colectivos, especialmente entre mujeres, en momentos importantes de transición entre dos mundo (como durante el parto). Esos ejemplos demuestran la clara presencia simbólica del agua en los procedimientos o mecanismos que utiliza el autor para reconstruir la memoria de sus orígenes.
\end{abstract}

Palabras clave: Mohand Mounsi; Le voyage des âmes; agua; identidad; memoria.

\section{Résumé}

Le romancier et chanteur français Mohand Mounsi revient à l'écriture autobiographique dans sa troisième ouvre publiée, Le voyage des âmes, afin de nous raconter le périple personnel de cet enfant de sept ans de sa Kabylie natale au bidonville de Nanterre. Dans ce voyage à l'intérieur des souvenirs, de la reconstruction de la mémoire et de l'identité interculturelle, l'eau aura un rôle fondamental, notamment dans les rites de la culture berbère. En ce sens, il faudrait mettre en évidence toute la transmission effectuée par la grand-mère Zina cette magicienne qui l'a initié et instruit dans le respect de la nature par le biais de la narration d'histoires et de légendes autochtones où le symbolisme de l'eau est très marqué. En effet, il s'agit d'une écriture qui évoque des rituels où l'eau constitue un élément primordial, qu'ils soient communautaires, comme ceux visant la protection des défunt dans leur passage de la vie à la mort, ou collectifs, spécialement entre femmes, lors d'important moments de transition entre deux mondes (comme durant l'accouchement). Ces exemples démontrent la valeur symbolique évidente de l'eau dans les procédés et les mécanismes utilisés par l'auteur en vue de reconstruire la mémoire des origines.

Mots-clés: Mohand Mounsi; Le voyage des âmes; eau; identité; mémoire.

\begin{abstract}
The French singer and novelist Mohand Mounsi goes back to an autobiographic style of writing in his third novel, Le voyage des âmes, and tells us about his personal journey as a seven-year-old child from his home town in Kabylia to the Parisian suburb of Nanterre. In this journey, an insight into his cultural identity which is full of personal memories, water plays a very important role, primarily in the rituals of the Berber culture. His grandma Zina, a significant figure in his life, was a kind of magician who taught him to respect nature through the native stories and legends she told where the symbolism of water as well as other rituals involving water held a significant importance. These ceremonies can be communal, for instance to protect the deceased in their path from life to death, or collective, particularly among women in crucial moments of transition between two worlds - giving birth. These are clear examples of the symbolic presence of water used by the author to rebuild the memory of his origins.
\end{abstract}

Keywords: Mohand Mounsi; Le voyage des âmes; water; identity; memory. 


\section{Introducción}

En este artículo pretendemos analizar la obra de Mohand Mounsi, Le voyage des âmes (1997). Nos centraremos en el papel del agua en los rituales que aparecen en la novela pero también en la función que puede tener este elemento en aspectos tan destacables en el autor como la memoria, la identidad y los orígenes, además también analizaremos otros elementos naturales relacionados con el agua como la lluvia, el sol, la luna, etc. Para ello hemos dividido el trabajo en tres partes: en la primera, abordaremos el contexto sociopolítico y daremos una visión general de la situación de la literatura de migraciones. Posteriormente, haremos una breve presentación de la escritura del autor para pasar a analizar la presencia y la función del agua en la novela. Finalmente, sacaremos unas conclusiones de conjunto sobre lo expuesto.

\section{Contexto sociopolítico y cultural}

Como expone Mohamed Ridha Bouguerra en su obra Histoire de la littérature du Maghreb, littérature francophone, la literatura magrebí, nace con la emancipación de los territorios africanos de Francia como Argelia, Marruecos y Túnez. Esta liberación del colonialismo emerge como rebelión intelectual y cultural ante el país galo. A raíz de estos acontecimientos surgen autores que quieren expresar su malestar, su visión y los motivos de esta revuelta a través de sus escritos como Driss Chraïbi (1926-2007) con su obra Le Passé simple (1954) o Succession ouverte (1962) donde los protagonistas rompen con las reglas y con lo establecido. En ellas también podemos encontrar los conflictos entre las diferentes generaciones con profundas reflexiones respecto al imperialismo y a la independencia del "poder colonial". Así pues, en esta literatura de liberalización del colonialismo, encontramos un evidente descontento ya que tanto el autor como los personajes no encuentran su sitio en la sociedad. Esta primera generación de autores del "malestar colonial" serán los antecesores de la llamada littérature beur.

En la década de los 70 del siglo XX, encontramos a una generación de escritores, como Mohand Mounsi o Tassadit Imache, que vienen de la euforia de la independencia colonial. Sin embargo, a diferencia de lo que podríamos esperar, lejos de plasmarse en sus obras una sensación de alegría u optimismo, se vislumbra todo lo contrario: un profundo descontento unido a un sentimiento de angustia y malestar. Esta desilusión aparece por la simple razón de que los valores culturales y sociales, que con tanto fervor defendía teóricamente Francia, tanto en sus territorios coloniales como en su propia casa, van decayendo pues toda una serie de ideales como la igualdad republicana no se cumplen. En este sentido, los inmigrantes, que van de las antiguas colonias a Francia, sufren un trato diferente en todos los aspectos de la vida social, política y cultural, especialmente dramáticos en el momento de buscar un empleo. Mohand Mounsi se hace eco de esta problemática y en obras como Territoire d'outre-ville (1995) muestra esta decepción mezclada con grandes dosis de amargura. Se trata de obras con clara intención política que se ofrecen como arma contra la violación de los derechos más elementales, la falta de referentes y la pérdida de valores socioculturales.

Pero no será hasta los años 80, gracias a los movimientos sociales propiciados por los propios inmigrantes, cuando veamos un verdadero despegue de este nuevo espacio literario. En este campo de la reivindicación activa, encontramos SOS Racisme, un movimiento social que se convertirá en asociación y que nace por el malestar de los inmigrantes de origen africano de los antiguos territorios coloniales respecto a Francia. SOS Racisme surge pues con un grupo de jóvenes que se movilizan por la puesta en marcha efectiva de los ideales republicanos de la sociedad francesa (liberté, égalité, fraternité) así como por la justicia ante los actos sociales de segregación y discriminación. Como vemos en su página web, poco a poco este movimiento irá evolucionando y pasará a ser una asociación bien articulada que lucha contra el racismo. Esto no sucederá hasta el año 1984 de la mano de su presidente, Harlem Désir. Además de SOS Racisme, encontramos otro colectivo de gran importancia mediática: La marche pour l'égalité et contre le racisme, conocida como La marche des beurs. El 15 de octubre de 1983, un grupo de jóvenes se concentran en Marsella en contra de los crímenes segregacionistas, reclamando justicia y luchando por los derechos sociales de los inmigrantes. Supone un comienzo fundamental en las reivindicaciones de estos colectivos que se extenderán a todo el país.

Así pues, como señala Jan Goes (2003:3) podemos distinguir cuatro generaciones que abarcan esta literatura de migraciones. Por un lado, antes de 1950, estarían los pionniers, que escribían bajo la colonización. Entre ellos destaca Chokri Khodja (con el seudónimo de Hassen Khodja Haldane) o Tahar Essafi. Luego encontraríamos a los aînés, que son aquellos escritores que han conocido y escrito en el contexto de las luchas por la emancipación y la independencia. Dentro 
de este grupo destacaría el novelista marroquí Driss Chraïbi. A continuación se situarían los grands frères et sœurs, que han vivido la independencia y la época postcolonial, y que están más vinculados con Francia por haber residido allí de forma temporal o definitiva. Empezarían a escribir a partir de los años 1970. En este grupo se situarían los autores sobre los que trabajamos de manera especial como son Mohand Mounsi o Tassadit Imache. Finalmente encontraríamos la nouvelle génération, compuesta por autores ya nacidos en Francia, calificados como beurs y donde podríamos situar a Faïza Guène, la otra autora sobre la que investigamos.

Como hemos podido ver, la literatura de migraciones se nutre y evoluciona gracias a los movimientos sociales que van surgiendo para se enfrentan con las opresiones raciales y sociales. Los autores, dependiendo de la época, reclaman y combaten abusos diferentes pero siempre con una misma base. Autores como Mohand Mounsi, Tassadit Imache o Driss Chraïbi luchan contra las injusticias étnicas y reivindican con sus novelas los derechos que les son denegados.

\section{Presencia y función del agua en Mohand Mounsi}

Nos centraremos a continuación en Mohand Mounsi, escritor y cantante nacido en Argelia, concretamente en la región de Cabilia, en 1951, y de nacionalidad francesa. Es autor de novelas como: La noce des fous (1990), La cendre des villes (1993), Territoire d'outre-ville (1995), Le voyage des âmes (1997) o Les jours infinis (2000). En su faceta como músico destacamos la publicación de su álbum L'aventure Motors, publicado el 27 de septiembre de 2010 un homenaje a Francis Dreyfus. De muy pequeño emigra con sus padres a Francia, a Nanterre, en busca de una vida mejor y crece en la periferia, desde temprana edad empieza a tener problemas con la justicia pero a su vez se enamora de la escritura y de la poesía cuando descubre a François Villon en las clases de literatura de la escuela lo que le apartará de las calles y de los conflictos con la justicia para acercarlo al arte como la música, la poesía, la literatura y la escritura.

En Le voyage des âmes el narrador nos relata en primera persona la vida, la partida y el retorno a la tierra natal de un joven argelino, que el lector tiende a identificar fácilmente con el propio Mohand Mounsi, aunque no se especifica claramente el nombre de este personaje y existen divergencias vivenciales entre autor y narrador. Vive en un pueblo pequeño de Cabilia, en una sociedad muy ligada a sus tradiciones. Huérfano de madre, que muere durante el parto, decide irse a Francia y buscar en Nanterre, donde ha emigrado su padre, una mejor vida y educación lejos de su abuela Zina, quien le ha enseñado todo sobre las costumbres y ritos de su cultura beréber, pero también lejos de su amor de infancia, Leïla.

La cultura beréber está muy presente en las novelas de Mohand Mounsi con el fin de marcar el origen y su identidad como inmigrante. En ellas la memoria y la identidad constituyen dos temas recurrentes y el agua es un hilo conductor que une ambos elementos. En su novela Le voyage des âmes podemos identificar varios ejemplos de cada uno de estos aspectos. El autor parte de la infancia del personaje principal rememorando tanto sus orígenes como la sabiduría popular y ancestral encarnada por su abuela Zina donde el agua tendrá un rol preponderante pero también tendrá presentes a diferentes personajes femeninos importantes en su vida como su madre, aunque no la llegó a conocer, o su amor de infancia Leïla quienes también intervendrán de forma directa o indirecta en los rituales donde el agua es el centro de atención.

Primeramente nos centraremos en la función del agua en los rituales ligados a las tradiciones transmitidas por la abuela Zina a través de todo un proceso iniciático, en el que participarán ella misma y el personaje principal e incluso alguna vez la misma madre del joven. En estos actos, el agua está muy presente y tiene un alto simbolismo. Estas ceremonias sirven igualmente para establecer y consolidar vínculos permanentes con la casa familiar y la memoria de los orígenes, especialmente emotivos en el caso del protagonista, ya que su madre murió durante su alumbramiento. «Avant de me laisser sortir de la maison, elle m’avait fait poser sur le seuil mon pied nu qu'elle avait baigné d'un peu d'eau. “Afin que ton pied se souvienne de ce seuil et t’y ramène”, avait-elle dit» (Mounsi, 1997: 13).

En este fragmento podemos ver de qué manera se establece una relación de estrecha intimidad entre la abuela Zina y el narrador. Este lazo se acentúa por el ritual de lavar los pies descalzos antes de abandonar el hogar. Este recurso sirve igualmente para anticipar al lector acontecimientos que ocurrirán después y que tendrán gran transcendencia en el devenir de los personajes. Esta escena y esta ceremonia también se pueden vincular claramente con la memoria, ya que el polvo de los pies nos recuerda a la tierra natal del personaje principal pero será la casa y en concreto el personaje de Zina quien haga referencia a la memoria pues una vez en Francia el personaje principal a través del agua tendrá presente estos 
aspectos que le transportarán a sus orígenes. En efecto, son los pies y, de manera simbólica, el polvo que se limpia con el agua, lo que dejará atrás el narrador cuando emigre, es decir su tierra, pero serán los pies lavados de manera ritual los que guardarán el recuerdo de los orígenes. Por lo que el polvo será el hilo conductor de la memoria que desata el ritual gracias a la presencia del agua así como por la presencia del personaje de la abuela Zina, quien lo inicia en este tipo de ceremonias.

El agua sirve igualmente para establecer fuertes vínculos entre el narrador y su madre, o más bien la memoria de esta pero también con su abuela, Zina. Como se puede observar, las figuras femeninas como Zina o Leïla siempre están presentes en las ceremonias ligadas al agua porque serán los personajes encargados de llevar al personaje principal a su tierra natal una vez emigre es decir, que el recuerdo de estos personajes desencadenado por el agua hará que el joven tenga presente en su memoria sus propios orígenes y todo lo que esto conlleva. Mohand Mounsi presenta a los personajes femeninos como una especie de guardianas o protectoras de este elemento, ya que cada vez que aparece el agua de manera ritual encontramos a una mujer. Además, las liturgias con el agua entre mujeres se presentan como ceremonias sagradas en las que la corporeidad siempre está presente y que de alguna manera siempre se vinculan con la memoria o los orígenes del narrador.

Quand le soleil montait au plus haut du ciel, et que les murs de la maison chauffaient comme les parois d'un four, Grand-Mère Zina rafraîchissait le corps de ma mère avec une serviette imprégnée d’eau. Chaque matin, elle allait au puits et tout au long du jour elle s'employait à laver le ventre de la jeune femme. Elle disait que l'enfant qui allait naître ne devait pas manquer d'eau, car il vivait déjà, qu'il entendait le bruit de l'eau couler sur la peau de sa mère, qu'il en sentait la fraîcheur, comme une pluie (Mounsi, 1997: 20).

Lo primero que nos llaman la atención de este fragmento es el empleo de antónimos como chauffaient-rafraîchissait que simboliza la naturaleza, ya que estas palabras están acompañadas por elementos naturales como el sol y el agua, elementos que rápidamente se ponen en la relación con el personaje de Zina, quien encarna la naturaleza y los rituales que se derivan de la misma. Por otra parte, podemos asociar el sol y el agua como fuentes principales que intervienen en el proceso del embarazo, del parto y en definitiva de la vida por lo que encontramos un vínculo entre estos elementos naturales, que simbolizan la naturaleza, encarnada por Zina, y el personaje de la madre. Como vemos, el agua es un elemento esencial en el universo femenino y en la transmisión familiar que se hace a través de las mujeres (abuela-madre-hijo). Sirve para marcar un vínculo inquebrantable que empieza antes del nacimiento y acaba después de la muerte. También son las mujeres las que van a buscarla al pozo, por lo que se establece una asociación entre los rituales íntimos y los elementos naturales como la lluvia. Así mismo, el agua en estos casos formará un enlace entre los lazos familiares, el agua y la mujer -la madre o la abuela- como elementos naturales que se asocian al personaje principal. Por otra parte, observamos un escenario idealizado por la memoria que acompaña a la ceremonia de lavar el cuerpo, y particularmente el vientre, de la embarazada. Este ritual se prolonga e intensifica en el momento del alumbramiento del niño, con la presencia del agua que discurre con su suave sonido. La descripción es especialmente poética y muestra a las dos mujeres en un acto de fusión corpórea y espiritual en el que la abuela se convierte en comadrona de su propia hija: abuela sabia, abuela maga, abuela tierra. Con lo que de nuevo, el lector vuelve a encontrar el agua y la mujer en un ritual natural que sella de alguna manera el vínculo afectivo-familiar entre la hija, la abuela y el nieto no nato. Por otra parte, encontramos otros elementos naturales, además del agua o la lluvia, que están presentes como la luna, que simbolizará la unión femenina entre la abuela y la madre pero al mismo tiempo vinculará al nieto con su abuela. De esta forma la luna actuará como agente poético que de alguna manera simbolizará el comienzo de la iniciación en las liturgias del nieto que acaba de nacer.

Les mains fortes de ma grand-mère m’ont mis au monde. Le ventre énorme de ma mère surgissait, pareil à une lune et Grand-Mère tordait la serviette au-dessus de sa peau. L'eau coulait en faisant son bruit doux, et Grand-Mère parlait à sa fille en caressant son ventre, ses seins, son visage renversé aux yeux fermés, elle essuyait la sueur qui coulait sur son front, dans son dos, et collait ses cheveux à ses joues. (Mounsi, 1997: 24).

Podemos concluir que el agua, e incluso el sol, durante el proceso de embarazo y alumbramiento no solo simboliza los lazos indestructibles que existen desde un primer momento entre madre e hijo sino que es sinónimo de vida en un sentido 
más amplio. De este modo el preciado líquido que emana de la tierra a través de los pozos forma parte de la vida de la comunidad y sirve para dar un sentido transcendente al momento del parto creando unos fuertes vínculos tanto en el entorno familiar como con la naturaleza. Además, la luna actuará como el agua es decir, que tendrá un rol que vincula a la familia con las tradiciones culturales y por ende con la naturaleza. Otro aspecto especialmente interesante es la corporeidad, presente en los rituales con el agua entre las mujeres, aquí en concreto en las caricias que la abuela Zina hace en el vientre, los senos y el rostro de su hija. Vemos claramente la importancia del matriarcado en la sociedad beréber y de qué manera se perfila la especial relación entre la abuela facilitadora de vida y el niño, un nexo afectivo que se intensifica tras la desaparición de la madre.

El agua será también un elemento esencial en las ceremonias relacionadas con las creencias populares ya sean de carácter mágico o religioso. En este sentido la abuela también será el pilar fundamental para la transmisión de las mismas al niño pasando la cultura beréber a la siguiente generación.

Grand-Mère Zina, alors, me montrait comment on pouvait résister à l'œil, avec les signes secrets que je devais répéter, en mettant la main devant son visage et en écrivant sur son front le nom de Dieu avec l'eau mêlée de cendres. Et elle m'apprenait comment effrayer les sorcières, en soufflant dans sa main ouverte un peu de sable. Elle me disait aussi le conte de cette sorcière, la noire, la cruelle, déguisée en esclave, qui mangeait le cœur des enfants pour rester immortelle. (Mounsi, 1997: 33).

En este fragmento podemos apreciar que el agua interviene como agente protector ante elementos malignos como las brujas, o las energías negativas que se transmiten a través de los ojos. Esa mezcla de agua y ceniza se convertirá en un elemento mágico que forma parte de una liturgia que invoca el nombre de Dios y ahuyenta a los malos espíritus convirtiendo así al agua en un elemento sagrado que junto a las cenizas lo podemos asociar a la memoria por su aspecto cultural. Podemos advertir que el personaje de Zina, en este fragmento, adquiere un rol más religioso y solemne al mismo tiempo que degenera en una especie de sacerdotisa que enseña al joven los procedimientos y los secretos religiosos de su cultura beréber, que este debe repetir para aprender bien cómo protegerse de estos entes maliciosos.

Querríamos insistir a continuación en la importancia que tiene el agua en la novela como elemento que preserva la memoria y marca la identidad del narrador en su periplo hacia una vida mejor lejos de la tierra natal. Todos las dudas existenciales sobre el sentido de la vida, los orígenes, las huellas del pasado, la proyección hacia el futuro e incluso las preguntas y las inseguridades que brotan en cuanto a su identidad como migrante, están marcados por el elemento acuático, ya que la presencia del agua en cualquiera de sus estados como el mar o la lluvia hará que personaje principal reflexione sobre su existencia.

Où allions-nous? C’est cela que j’aurais voulu demander à mon oncle. Mes pensées se heurtaient suivant le rythme des vagues. Je croyais que je n'étais plus le même, que plus jamais je ne serais le même. Déjà la mer me séparait de ma grand-mère, de Khalti Fathia, d’Azzedine, de tout ce que j’avais été. Je voudrais être capable de me souvenir dans chaque détail de tout ce qui s’est passé ce jour-là, pour le revivre maintenant. (Mounsi, 1997: 15-16).

Evidentemente el agua del mar es un elemento esencial en todo este cuestionamiento vital y que actuará como un desencadenante de reflexión existencial llevando al personaje a recapacitar sobre su identidad de inmigrante. Como vemos, a través del ritmo de las olas y la observación del mar, el narrador empieza a meditar sobre su propia identidad y toma conciencia de que al alejarse de sus orígenes, encarnados concretamente en los personajes de la abuela Zina y de sus amigos de infancia Khalti, Fathia y Azzedine, ya no volverá a ser el mismo. Toma conciencia de que se trata de un viaje definitivo, o al menos completamente transformador. El mar sirve pues para marcar esa separación simbólica entre la tierra de origen y su incierto destino. Este aspecto es algo irónico porque el elemento que hasta este momento era un enlace entre su abuela es decir, orígenes, cultura, tierra natal, etc. ahora es un elemento que le separa de todo esto. Una vez en Francia, el agua en forma de lluvia crea un sentimiento de profunda nostalgia en el narrador y permite la vuelta a los recuerdos de la infancia a través de un estado de ensoñación, adquiriendo el agua un rol negativo, por primera vez en la obra siendo un elemento psicológico emocional que marca la existencia del personaje en el momento de la llegada al 
país de acogida. «En écoutant tambouriner la pluie sur le toit de la chambre, je ne rêvais plus que de cirque et de camions, des gens du voyage roulant dans la poussière des chemins. Des nuits durant, c'est avec ce rêve que je me suis endormi, enroulé dans ma couverture» (Mounsi, 1997: 77).

Como podemos constatar, el sonido repetitivo del agua, en este caso de lluvia, adquiere un valor poético y desencadena un sentimiento de repliegue sobre sí mismo, de toma de conciencia de su condición de inmigrante y de fusión con el resto de seres errantes. Sin embargo el narrador no permanecerá o se regocijará en ese estado de nostalgia de la tierra perdida e intentará integrarse en la sociedad de acogida, especialmente gracias a su gusto por la poesía y la lengua, motivado por otra mujer muy importante en su vida, su profesora de lengua francesa. «En moins d’un an, j’avais rattrapé mon retard. Je savais lire et écrire, calculer. Je me passionnais pour le français, la poésie. Ma chance fut cette institutrice qui s’était prise d'affection pour l'enfant presque sauvage que j’étais» (Mounsi, 1997: 80).

En esta nueva etapa de iniciación e inmersión en la cultura francesa a través de la lengua, su profesora se convertirá en una especie de sustituta de la abuela Zina que lo instruirá en el conocimiento de otros valores esenciales para la dignidad humana alejándolo de esta forma de la violencia y de los problemas con la justicia. Se opera por tanto una apreciación de la cultura de acogida a partir de la escuela y la educación que desgraciadamente sus padres no tuvieron, y que le permitirá salir de ese estado casi “salvaje” en el que se encontraba. «Elle voulait que j’apprenne le langage, les mots que mon père et ma mère n’avaient jamais pu réussir à lire» (Mounsi, 1997: 82).

De esta forma el autor hace una diferencia clara entre su situación en su tierra natal y su identidad como inmigrante y todo lo que ello conlleva como la educación. Con este fragmento encontramos el objetivo de diferenciar de forma directa las dos generaciones; por una parte la del padre, quien al no tener unos estudios se le dificulta su integración social en Francia y por otro lado la generación del personaje principal, quien aun siendo inmigrante puede acceder a una educación como cualquier autóctono y prosperar social y económicamente.

\section{Conclusiones}

Como hemos podido ver, la literatura de migraciones se nutre y evoluciona gracias a los movimientos colectivos que van surgiendo para luchar contra las opresiones raciales y sociales. Dependiendo de la época, los autores reivindican cuestiones distintas y combaten abusos diferentes pero siempre desde un mismo posicionamiento. A través de su escritura y de sus testimonios, escritores como Driss Chraïbi, Mohand Mounsi, Tassadit Imache o Faïza Guène luchan contra las injusticias sociales y defienden los derechos de los que se ven privados debido al pasado colonial, a sus orígenes y a diferentes razones sociopolíticas.

Estos movimientos sociales surgidos en los años 80 constituyen una fuente de inspiración esencial en la escritura de Mohand Mounsi, así pus sus obras forman parte de la protesta y de la lucha de estos movimientos reivindicativos, que se iniciaron en la primera parte de la década de los 80 hasta bien entrados los 90 . El autor, a través de sus obras y en concreto Le voyage des âmes, intenta llegar al lector con la intención de reivindicar su sitio en la sociedad francesa sin renunciar por ello a su cultura beréber y a su tierra de origen.

Identidad y memoria aparecen pues unidos de manera indisoluble en esta novela en la que Mohand Mounsi, con su particular escritura autobiográfica, nos muestra, a través del agua y de otra serie de elementos como la corporeidad, la luna o el sol y de una serie de personajes femeninos entre los que destaca su abuela Zina o la madre del personaje principal todo aquello que lo identifica tanto con sus orígenes en Cabilia como con su realidad de inmigrante en un suburbio parisino de Nanterre. Finalmente, los orígenes será otro aspecto a destacar en las obras de Mohand Mounsi y que en $L e$ voyage des âmes también hemos trabajado. Este tema está vinculado con la memoria aunque en ciertas ocasiones se ha desvinculado para asociarse con el agua con el fin de hacer reflexionar al personaje principal sobre su existencia de inmigrante. 


\section{Referencias bibliográficas}

BouguerRA, Mohamed Ridha (2010). Histoire de la littérature du Maghreb, littérature francophone. Paris: Ellipse.

GoEs, Jean (2003). «Littératures francophones du monde arabe. La littérature “beur” en Romaniac, $\mathrm{n}^{\circ} 90$.

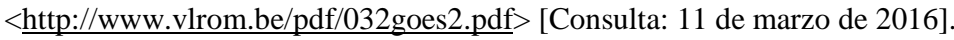

MoHAND, Mounsi (1997). Le voyage des âmes. Paris: Stock.

Sos RACISME. < http://sos-racisme.org> [Consulta: 13 de marzo 2016]. 